International Journal of Managing Information Technology (IJMIT) Vol.10, No.3, August 2018

\title{
“DESIGN AND IMPLEMENTATION OF AN ENTERPRise RESOURCE PlanNing SyStem WiTH VIRTUAL DESKTOP INFRASTRUCTURE FOR ALSAID MILlS - SUDAN"
}

\author{
Ahmed Taha Mirghani Ahmed and Maria Emmalyn Asuncion De Vigal Capuno
}

Faculty of Information Technology, Future University, Khartoum, Sudan

\begin{abstract}
Alsaid Mills is a new business in the new market of packaged bakeries, they deliver quality croissant and cake that stays fresh for a week, which has gained them a greater advantage in the market, the company is continually broadening their scope of operation and with time the day to day operations are becoming time consuming without the existence of an Enterprise Resource Planning (ERP) system.The proposed ERP system is constructed on four (4) basic modules: the Finance, Inventory and Sales, Manufacturing and Procurement; as these departments represent the main functional point for Alsaid Mills.In addition, the document explains the structure of the proposed Virtual Desktop Infrastructure that is considered an additional feature that could construct a solid foundation for the Information Technology (IT) Department at Alsaid Mills to provide their users with innovative solutions to work from any computer device without the need for high performance computers.It is proposed that the company should adopt an ERP coupled with a Virtual Desktop Infrastructure (VDI) that would ease the administration of the ICT Infrastructure and allows for an innovative platform for the staff at Alsaid Mills.The adopted methodology is the water fall model which is a sequential (non-iterative) design process, used in software development processes, in which progress is seen as flowing steadily downwards (like a waterfall) through the phases of conception, initiation, analysis, design, construction, testing, production/implementation and maintenance.
\end{abstract}

\section{KEYWORDS:}

Enterprise Resource Planning (ERP), Virtual Desktop Infrastructure (VDI), Centralized Server, ERP Implementation

\section{INTRODUCTION}

Enterprise Resource Planning (ERP) software has become increasingly in use more commonlly in a lot of today's businesses. The software has been adopted in many organizations towards improving business performance. The theory of business performance can be operationalized as financial advantages by the firms, operational improvements for the organization or intangible gains for the institution.

Multinational companies worldwide are looking toward reengineering and cost cutting and often combined their ERP project with the breaking down of country barriers for Manufacturing sites, Centers of Distribution, ERP is seen to be a trampoline for Internet technology, and solutions such as Supply Chain Management (SCM) and Customer Relationship Management (CRM) came to the fore. 
International Journal of Managing Information Technology (IJMIT) Vol.10, No.3, August 2018

Sudanese research centers such as Nile Center for Technology Research (NCTR) are developing ERP software using the open sources ERP known as Odoo, with more than 6 years of experience in Software Development and Engineering and not less than 3 years in applying Open ERP in Sudanese Governmental and Private Sector Companies; NCTR built a team of 30 qualified personnel able to perform all ERP implementation and consulting tasks. NCTR is currently expanding its capacity to accommodate even more staff in relation to its software based products.

Alsaid's Mills Ltd. since its inception was concentrated on providing quality wheat to the Sudanese community which considers wheat to be the stable food for them, the company currently provide a variety of products that are produced from wheat as the competition on the wheat market is growing rabidly with the emergence of the new companies that are adopting new technologies and buying with bigger quantities, the difficulty increases as the wheat is considered a strategic commodity and the prices are controlled by the government, which prevents companies like Alsaid's Mills from reselling the wheat that they buy from the main providers who purchase the wheat from external sources.

"The Companies that tend to struggle the most [with ERP] are the ones that lack upper management level involvement," says Daniele Fresca director of Marketing, IQMS, and a provider of industry-specific ERP solutions. "Resources at the lower level tend to not be educated and engaged with the implementation project without senior level involvement," she says. That said, executives do not need to get to the point of knowing every single configuration detail. But [they need to] be aware of the issues that are causing delays to the project.

However, the top management at Alsaid Mills seems to give a very great priority in supporting and implementing the ERP system at their company, and are keeping a close eye on the progress of the analysis of system details.

The Finance Department calculates the return and expired products and this process takes and additional time in the morning to release the new distribution orders, this manual system is causing the delay of the product deliver to the customers.

There is a need of a virtual desktop infrastructure as the company is willing to invest in a properly configured infrastructure that lowers down the operational expenses and provide quick and easy "workstation" provisioning, centralized patch management, standardized security configurations, and secured data.

It is in this context that the "ERP System with Virtual Desktop Infrastructure for Alsaid Mills Sudan" was proposed, designed and developed by the proponent, which will assist the staff of Alsaid Mills to improving the overall performance of the staff and the company as well, and the focus of this paper will be on the operational and intangible gains resulting from ERP implementation (which will be operationalized by many variables tested in this study).

The ERP tools that a company selects often depend upon the specific business processes it wants to improve, and also upon whether it is selling products or services. Businesses that sell products often have manufacturing, supply chain and distribution functions that the ERP system must address. For organizations that sell services, ERP capabilities such as project management for service engagements and support for field services and sales operations are very important.

Deploying an enterprise resource planning (ERP) system is an expensive proposition, not just in terms of licensing dollars (Service Level Agreements) and maintenance, but in terms of dedicated 
resources and time, there for this proposal will discuss how two start the gradual implementation of the ERP.

The proposal includes a virtual desktop infrastructure (VDI), which is the practice of hosting a desktop operating system within a virtual machine (VM) running on a centralized server. VDI is a variation on the client/server computing model, sometimes referred to as server-based computing. The term was coined by VMware Inc.

The proposed system is an open source ERP system, Open source ERP is an enterprise resource planning (ERP) software system whose source code is made publicly available. The open source model allows companies to access the ERP system's code and customize it using their own IT department instead of paying extra for vendor customization services and licensing, as is typically the case with closed source programs.

Alsaid's Mills Ltd. Is a local bakery business in Sudan and since its inception it was concentrated on providing quality wheat to the Sudanese community which considers wheat to be the stable food for them, the company currently provide a variety of products that are produced from wheat as the competition on the wheat market is growing rabidly with the emergence of the new companies that are adopting new technologies and buying with bigger quantities, the difficulty increases as the wheat is considered a strategic commodity and the prices are controlled by the government, which prevents companies like Alsaid's Mills from reselling the wheat that they buy from the main providers who purchase the wheat from external sources.

The research main objective is to design, develop and implement an ERP System that enables the staff of Alsaid Mills to perform the majority of their business operations, while providing a report dashboard that enables the top management to have complete visibility into all the important processes, across various departments of the organization.

\section{Specifically, It Aimed To ACHieve The Following:}

1. To design a module that would enable the finance department to oversee the financial transactions of all departments including those of external entities like customers and suppliers.

2. To design a module that would enable the users to create purchase requests and notify their managing directors to approve the purchase request and then sending it to the procurement department.

3. To create a module that would enable the store keeper from confirming incoming and outgoing sales orders.

4. To create a module that would enable the production manager from calculating the cost of producing a certain quantity of a product.

The proposed system focused on supporting the finance, inventory, sales, procurement, production and human resources departments while providing the administrators at Alsaid Mills with a reporting interfaces that allows them to oversee the current status of their businesses.

The accounting module will cover invoicing by managing recurring billings, and easily track payments and controlling supplier invoices, while maintaining a very flexible method of payment for the customers, if the customers pays for a single payment with two checks the system will able to handle that payment.

The account reconciliation will be $90 \%$ simpler than the manual process as the system will require a bank statement in Comma Separated Values (.CSV) file format extension, in order to 
International Journal of Managing Information Technology (IJMIT) Vol.10, No.3, August 2018

perform the reconciliation, then the bank statement will be compared to the local general ledger account, and if the American embargo is lifted, international banks that provide online bank synchronization will enable the system to synchronize over the cloud which would enable the company to easily reconcile the local accounts on the system with their bank accounts, the reconciliation report will enable the financial managers from seeing the current balance in their general ledger and the latest bank account and every entry that is responsible for the difference if there is any, however this feature will not be activated in the proposed system, as the banks that support online bank statement are not yet offering their services in Sudan.

The human resource (HR) module will enable the HR manager from viewing all important information for each department at a glance. Restrict visibility of sensitive information to just HR managers, or make other information public for all employees to see such as receiving alerts for any new leave requests, allocation requests, applications, appraisals, and more.

The module will also include tracking of the employee hours worked and sort by project, client, or tasks. Easily access statistics to record and analyze timesheets as well as check each employee's attendance. Integrated accounting automatically posts reports based on time spent in projects providing real-time data.

Although the time tracking and attendance module will support bio-metric and RFID devices to be integrated with it, this system will only cover the calculation process that occurs after the employee attendance data in entered to it, meaning the HR officers or assistance should insert the attendance data manually as the cost of procuring an RFID or fingerprint device would beyond the development budget of this project, and there for would complicate the process of testing this feature.

The quality control will be included as a group of users that will be able to see the malfunctions of the production and view the complaints of the production team, this is considered a partial module from the production module.

The products and production lines that will be considered will be the cream cheese croissant, chocolate croissant, vanilla flavored cake and chocolate flavored cake, other production lines that are part of Alsaid Mills will not be covered in any of the modules of the proposed ERP.

\section{TeChNiCAL BACKGROUND}

AL said Mills currently has 10 users that are using a direct connection to the internet, all users are connected to a wireless based Local Area Network (LAN), meaning the majority of the users are connecting to the internet with a wireless adapter connected to their computers and there is no intranet or shared resources between them locally.

The methodology that the proponent used in accomplishing this project was water fall Methodology since it was the first Process Model to be introduced. It is also referred to as a linear-sequential life cycle model. It is very simple to understand and use. In a waterfall model, each phase must be completed before the next phase can begin and there is no overlapping in the phases.

AL said Mills have a great interest in finding a very suitable middle ground solution that could simplify the management of their computer resources while increasing the flexibility and mobility for their end users, while maintaining a well standardized and professional infrastructure that 
International Journal of Managing Information Technology (IJMIT) Vol.10, No.3, August 2018

could enable them to expand for their future needs, all under a reasonable budget. Listed below are the hardware requirements for developing this project:

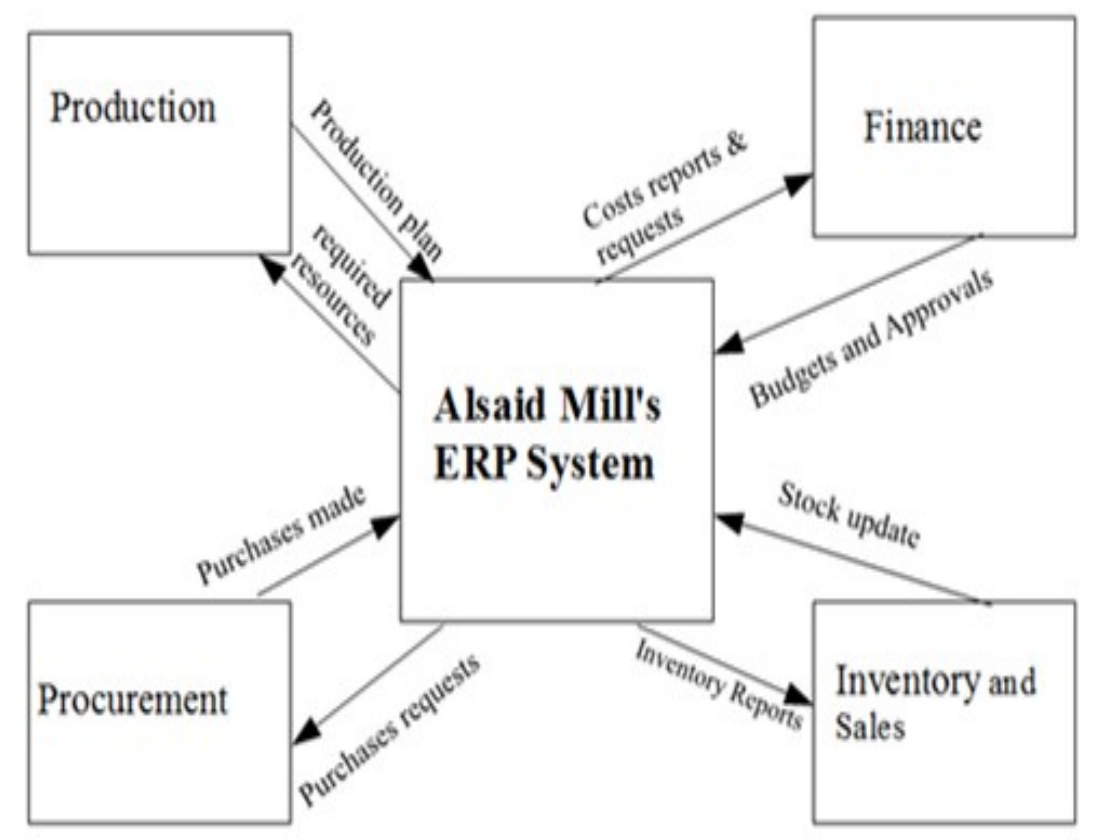

Figure 1. Conceptual Framework of the ERP with VDI

The ERP system created was basically a PHP based system with accounting, inventory, sales, manufacturing and production. However, the system also included VDI that in itself requires a group of software's to be installed, listed below is the list of software's that would be required.

For a complete implementation, it is suggested that the proposed network infrastructure is a cabled network infrastructure using fiber optics cables for connecting between the different buildings within the facility, the fiber connections will serve as uplinks that connect the different departments in a mesh topology, and for the cabling within every department a CAT6 connection will be linking the workstations to nearest access switch.

The network design created for the development and testing of the VDI and ERP configuration is described briefly in the figure below: 
International Journal of Managing Information Technology (IJMIT) Vol.10, No.3, August 2018

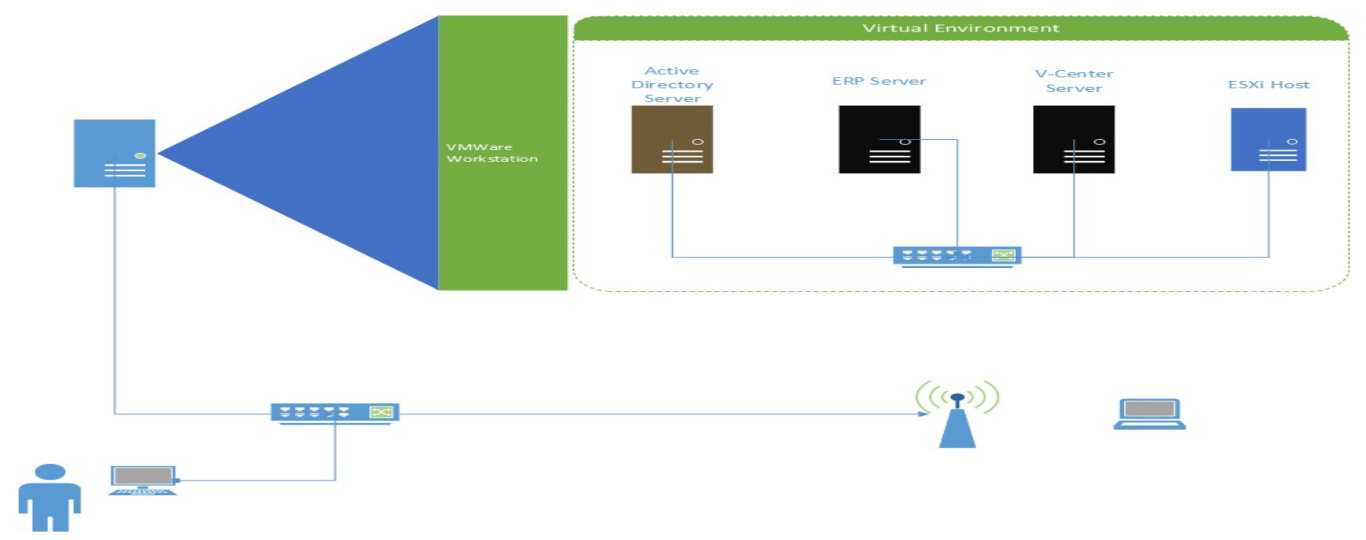

Figure 2. Network Design for ERP with VDI

In order to prepare for the VDI in the implementation the internal network of the company needs to be using a very reliable LAN, as the VDI main disadvantage is that it depends mainly on the network to deliver its services, additionally the network must have redundant fiber optics connectivity to reduce the downtime in case of any network equipment failure.

\section{Design And Methodology}

Adopting the conceptual approach for developing and customizing the ERP system and highlighting the roles and actions for every system user, below the UML design of the system:

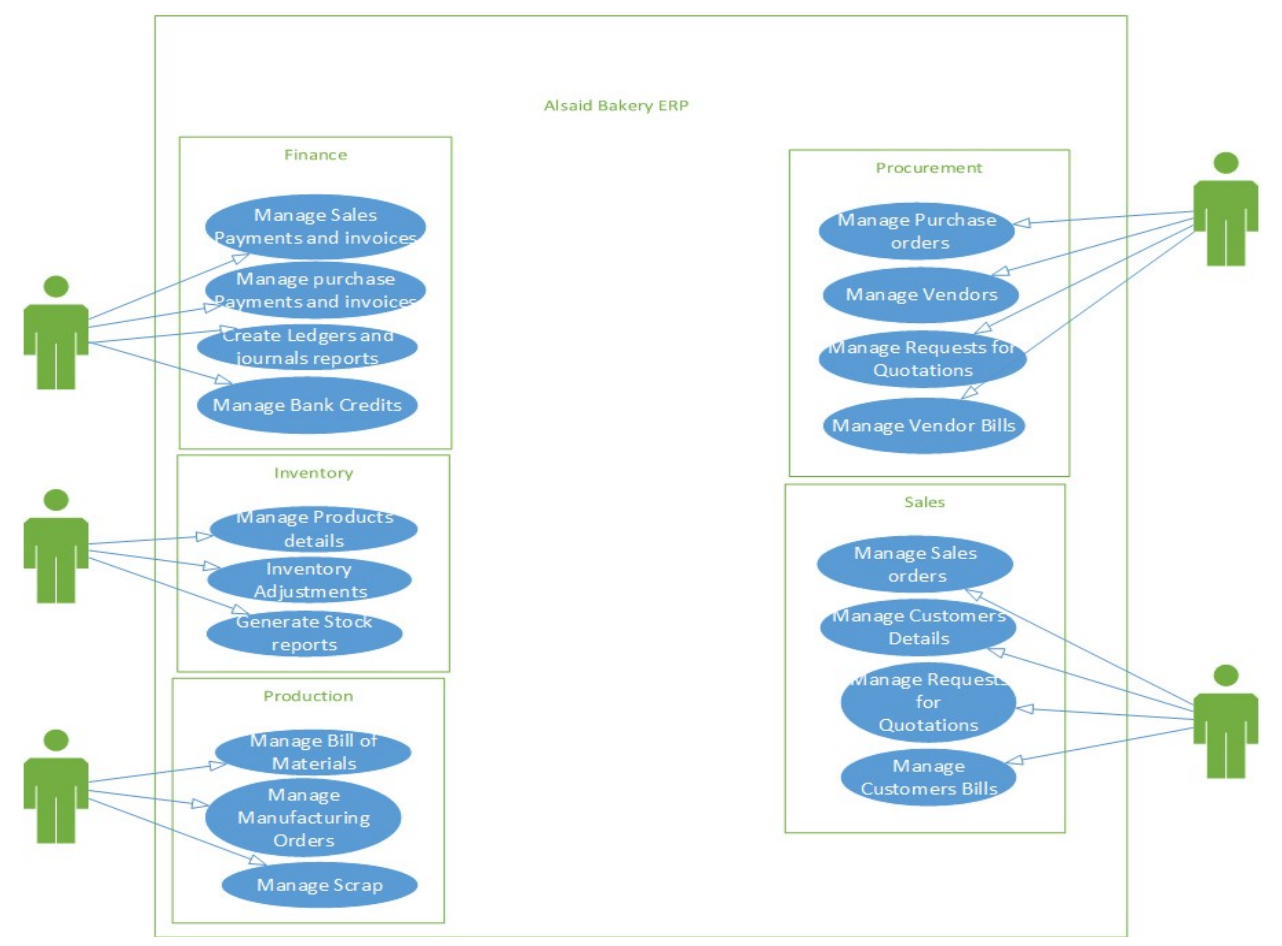

Figure 3. Use Case Diagram 
International Journal of Managing Information Technology (IJMIT) Vol.10, No.3, August 2018

\section{Results AND Discussions}

The alpha testing conducted in the proposed system determined the significance, or critical nature, of the application system to the business at Alsaid Mills and determines the types of tests required by each testing task to Identify the need for converted data from legacy systems or other sources as well as to determine the need for a systems integration test by identifying key system interfaces, in order to Identify performance assurance requirements.

The scrum methodology is a type of agile methodology that could assist with the rabid development of applications, which could enable faster development of testing requirements by directly using key project deliverables, earlier identification of testing requirements, independence of testing from development tasks and resources, well-defined tests and progressive and additive test tasks.

The testing focuses on two aspects, ERP module test and VDI integration test being the key ingredients in the development of the proposed system.

The following responses illustrates the aspects that the developer tested while developing the system while, the following test is done by other developers who have not participated in this project so as to provide a more effective testing mechanism.

1. The system interface is very friendly and usable and not complex, there would be no need for a specialized ICT staff to train the users on how to perform the regular operations as the system is self-explanatory and guides the user's actions with the interface.

2. The system is consistent with the interface through all users' interfaces.

3. The system requires no prior knowledge for the users to be able conduct day to day operation.

The beta test was conducted for a span of 6 users who are part of Alsaid Mills, the test was conducted over 2 days, the users were head of departments or their technical representatives and the results of the test are summarized as below.

Two users strongly agreed that the system helped them to more effective and productivity, another two users agreed that the system helped them become more productive, while one user remained undecided, furthermore 1 user disagreed as he wasn't able to foresee the impact of the system on the long term.

As for the friendliness of user interface and the ease of use 6 users agreed that the system is user friendly, however the commented on the system would require training for it to be used across the organization by other users who have little experience with systems.

In addition, four users agreed that the system was able to accomplish in a faster manner than the usual way of preforming specially for the manufacturing and supply chain, 2 users agreed that they can use the system successfully every time while two remained undecided about their ability to use the system successfully every time, and the remaining two users disagreed.

Four users expressed their satisfaction with the system while the remaining two think that the system should be able to perform more complex calculations regarding the costing space management in the ware house, the same ratio of approval applies when the users were asked if they would recommend the system to the remaining staff or friends within the company. 
International Journal of Managing Information Technology (IJMIT) Vol.10, No.3, August 2018

Recommendations for the users included the additional calculation features regarding the warehousing space and item manufacturing cost according to the HR module, these calculations were not implemented due to the fact they are beyond the scope of the project.

\section{CONCLUSIONS AND RECOMMENDATIONS}

Based on the results and discussions presented in the previous chapters, the following conclusions are hereby drawn: that a module has been designed to enable the finance department to oversee the financial transactions of all departments including those of external entities like customers and suppliers; that a module has been designed to create purchase requests and notify their managing directors to approve the purchase request and then sending it to the procurement department; that a module has been designed to enable the store keeper from confirming incoming and outgoing sales orders; and that a module has been designed to enable the production manager from calculating the cost of producing a certain quantity of a product.

Finally, based on the results and discussions presented in the previous chapters and conclusions drawn, the following recommendations are hereby proposed: that Alsaid Mills should implement the designed and developed system to enable them to have an effective reporting mechanism that enables the top management to be able to make their decisions in a timely and effective manner; and that the first line staff of the different departments use and implement the system including the proposed procedures and guidelines to eliminate redundant processes and organized activities and work flow required to perform internal paper work; and that the future researchers should add more features to the developed system by either allowing for the integration of a mobile application and/or allowing the system to be accessed remotely with more customized reports with possible inclusion of e-commerce and customer relationship management.

\section{REFERENCES}

[1] Ahmed A. Elragal and Ayman M. Al-Serafi (2011). "The Effect of ERP System Implementation on Business Performance: An Exploratory Case-Study". German University in Cairo (GUC), New Cairo City, Egypt.

[2] Despina Galani (2010). "The Impact of ERP Systems on Accounting Processes". Efthymios Gravas Antonios Stavropoulos.

[3] John Gunson (2004), "Implementing ERP In Multinational Companies: Their Effects On The Organization And Individuals At Work". University of Geneva.

[4] Nkosinathi Bitsini (2015). "Investigating ERP Misalignment between ERP Systems and Implementing Organizations in Developing Countries". University of Cape Town, Department of Information Systems, and South Africa.

[5] Rinoj P K (2014). "Impact of Implementing ERP in Indian Manufacturing Organizations". Faculty member, centre for management studies kannur university main campus, mangattuparamba kannurkerala 670567, paripex - Indian journal of research.

[6] Sergio Joao Teixeira Congo (2016). "Information Systems Management". International Jounral of Information Technology Convergence and Services (IJITCS) Vol. 6, No. 2/3.

[7] Suha Afaneh, Issam AlHadid and Heba AlMalahmeh (2015). "Relationship Between Organziational Factors, Technological Factors and Enterprise Resource Planning System Implementation". International Journal of Managing Information Technology (IJMIT) Vol. 7, No. 1. 